$0-5)$. CRBSI patients had significantly more PN infusions/ week (7, range $2-7$ vs 7 , range $1-7 ; \mathrm{P}<0.0001)$, presence of enterocutaneous stoma $(71.3 \%$ vs $27 \%$; $\mathrm{P}<0.0001)$, double-lumen CVC $(24.1 \%$ vs $4.8 \%$; $\mathrm{P}<0.0001)$, tube feeding $(38.9 \%$ vs $23.8 \% ; \mathrm{P}<0.05)$ and less oral/enteral feeding $(53.7 . \%$ vs $77.8 . \%$; P $<0.0005)$ compared to patients with no episodes of CRBSI.

Motility disorder group showed highest risk of CRBSI (HR 2.1; [95\% CI 1.84-3.21]; P <0.00001), total episodes of CRBSI $(61.3 \%$ vs SBS $31.8 \%$ and Ent $27.6 \%$; $<<0.0001)$ and CRBSI rate/1000 catheter days (motility disorder 2.7/1000, SBS $1.17 / 1000$, Ent $1 / 1000 ; \mathrm{P}<0.0001)$.

Log-rank survival analysis showed that frequency of $\mathrm{PN}$ infusion/week (HR 1.3; [95\% CI 1.10-.1.51]; P <0.0001), enterocutaneous stoma (HR 3.9; [95\% CI 1.95-7.76]; P $<0.0001$ ), absence of ICV (HR 2.37; [95\% CI 1.17-4.81]; $\mathrm{P}<0.05$ ), double-lumen CVC (HR 2.51; [95\% CI 1.703.86]; $\mathrm{P}<0.01$ ), age under 5 years (HR 2.26; [95\% CI 2.16-3.39]; $\mathrm{P}<0.000001)$ and male sex (HR 2.51; [95\% CI 1.64-3.86]; $\mathrm{P}<0.00001)$ were significantly associated with higher CRBSI rate. Conversely oral/enteral feeding significantly reduced the risk of CRBSI (HR 0.54; [95\% CI 0.47-0.98.]; $\mathrm{P}<0.001)$. COX multivariate analysis showed that only enterocutaneous stoma, age $<5$ years and doublelumen CVC were independently associated with a higher risk of CRBSI.

Conclusion Almost half of the children receiving home PN for IF do not develop CRBSI. Children with motility disorder are at highest risk of CRBSI. Moreover, the presence of enterocutaneous stoma, double-lumen $\mathrm{CVC}$ and age $<5$ years significantly increase the risk of developing CRBSI. These risk factors should be considered in the management of home PN in children with IF.

\section{P14 CLINICAL GENOMICS FOR THE DIAGNOSIS OF MONOGENIC FORMS OF INFLAMMATORY BOWEL DISEASE: THE 2020 ESPGHAN POSITION PAPER AND ITS IMPLICATIONS FOR UK SERVICE PROVISION IN 2021}

${ }^{1} \mathrm{Holm} \quad \mathrm{H}$ Uhlig, ${ }^{2}$ David Wilson, ${ }^{3}$ Jochen Kammermeier, ${ }^{4}$ Fevronia Kiparissi, ${ }^{4}$ Kimberly Gilmour, ${ }^{2}$ Richard Russell. ${ }^{1}$ University Oxford; ${ }^{2}$ University of Edinburgh; ${ }^{3}$ Evelina Hospital; ${ }^{4}$ Great Ormond Street Hospital

\subsection{6/flgastro-2021-bspghan.25}

Background It is important to identify patients with monogenic IBD since management including response to biologics and surgery plus the role of stem cell transplantation may differ from classical IBD. We report on the 2020 Position paper of the PORTO group of ESPGHAN for the use of genomics to diagnose monogenic causes of IBD.

Methods Paediatric IBD specialists from the Paediatric IBD Porto group of the European Society of Paediatric Gastroenterology, Hepatology and Nutrition (ESPGHAN) and specialists from several monogenic IBD research consortia reached a consensus of standard of care. Our systematic literature review covered indications, technologies (targeted panel, exome and genome sequencing), gene panel setup, cost-effectiveness of genetic screening, and requirements for the clinical care setting.

Results Next-generation DNA sequencing technologies are recommended to diagnose monogenic causes of IBD in routine clinical practice, embedded in the setting of multidisciplinary patient care. Routine genetic screening is not recommended for all IBD patients but instead genetic testing should be considered in the context of age of IBD onset (infantile IBD, very early onset IBD, paediatric or young adult IBD) and on further key criteria such as family history, relevant comorbidities and extraintestinal manifestations. Genetic testing is also recommended in advance of hematopoietic stem cell transplantation. We present a diagnostic algorithm that includes a gene panel of seventy-five monogenic IBD genes. We discuss how these recommendations can be implemented from 2021 onwards into the UK NHS health care system. Lastly, we present a UK-focused health care utilisation pathway highlighting the available UK clinical resources, clinical targeted panel sequencing and exome sequencing strategies in the UK, and regional immune validation pathways.

Summary Genomic technologies should be considered an integral part of patient care to investigate patients at risk for monogenic forms of IBD in the UK.

\section{P16 DIAGNOSIS AND MANAGEMENT OF FUNCTIONAL GASTROINTESTINAL DISORDERS: A CLINICAL AUDIT}

'Aimee Staunton*, ${ }^{1}$ Amelia Kataria Golestaneh*, ${ }^{2}$ Stephen Allen, ${ }^{2}$ Manjula Velayudhan Nair. 'University of Liverpool School of Medicine; ${ }^{2}$ Alder Hey Children's NHS Foundation Trust, Liverpool, UK; * Joint first authors

\subsection{6/flgastro-2021-bspghan.26}

Background Functional gastrointestinal disorders (FGIDs), now understood as disorders of gut-brain interactions, are a group of recurring gastrointestinal symptoms which after appropriate medical evaluation cannot be attributed to another medical condition. Clinical evaluation and management remain challenging. The recently updated Rome IV criteria are symptombased guidelines enabling classification and prevalence estimates of childhood FGIDs.

Aims To determine the prevalence of FGIDs amongst children presenting to Alder Hey gastroenterology outpatient clinics according to Rome IV criteria. To compare Rome IV with clinical diagnoses and describe clinical management.

Methods The referral letters and case records of all children attending gastroenterology clinics in January 2019 were

Abstract P16 Table 1 Diagnoses according to Rome IV criteria and clinical assessment and clinical management

\begin{tabular}{|c|c|c|c|c|}
\hline \multicolumn{2}{|c|}{$\begin{array}{l}\text { Rome IV diagnosis } \\
\mathrm{N} \text { definite/probable (\%) }\end{array}$} & \multicolumn{2}{|c|}{ Clinical diagnosis $\mathrm{N}(\%)$} & Clinical management $\mathrm{N}$ \\
\hline \multirow[t]{8}{*}{ IBS } & $\begin{array}{l}24 / 3 \\
(42.9)\end{array}$ & IBS & $\begin{array}{l}11 \\
(40.7)\end{array}$ & $\begin{array}{l}\text { Dietary review/ } \\
\text { modification } 11\end{array}$ \\
\hline & & Abdominal pain & $\begin{array}{l}6 \\
(22.2)\end{array}$ & $\begin{array}{l}\text { Anti-spasmodic } 8 \\
\text { Stool softener/laxative } 8\end{array}$ \\
\hline & & Functional pain & $\begin{array}{l}3 \\
(11.1)\end{array}$ & $\begin{array}{l}\text { PPI } 4 \\
\text { Symptom/stool diary } 2\end{array}$ \\
\hline & & $\begin{array}{l}\text { Non-specific } \\
\text { symptoms }\end{array}$ & $2(7.4)$ & $\begin{array}{l}\text { Psychological therapy/ } \\
\text { review } 2\end{array}$ \\
\hline & & Cyclic vomiting & $1(3.7)$ & Threadworm eradication \\
\hline & & Cow's milk allergy & $1(3.7)$ & 2 \\
\hline & & $\begin{array}{l}\text { Gastritis/ } \\
\text { constipation }\end{array}$ & $1(3.7)$ & $\begin{array}{l}\text { Anti-diarrhoeal } 2 \\
\text { Probiotic } 1\end{array}$ \\
\hline & & None given & $2(7.4)$ & \\
\hline
\end{tabular}

